\title{
La singularidad de un cantón como motivo para alfabetizar culturalmente en Sarchî*
}

\author{
Saray Córdoba Conzález \\ Universidad de Costa Rica
}

"Alfabetizarse no es aprender a repetir palabras, sino a decir su palabra".

Paulo Freire

"La lectura del mundo precede siempre a la lectura de la palabra y la lectura de ésta implica siempre la continuidad de la primera" escribió el maestro Paulo Freire. Para él la palabra tiene dos fases indisolubles: la acción y la reflexión, que relacionadas dialécticamente establecen la praxis, que para él es la práctica transformadora. Por ello, cuando leí el texto de Alicia y Gilberto no pude evitar la evocación a P. Freire porque su propuesta tiene intenciones transformadoras por medio de la transversalidad que busca modificar la pasividad que sobresale en nuestra educación costarricense para que mediante actividades participativas, reflexivas, investigativas, lecturales y observacionales el y la discente puedan trascender esa pasividad y llegar a la praxis, orientados por la docente.

Parodiando a Freire, quiero insistir en que la alfabetización -cultural en este caso- se da a partir de la realidad misma, pues después de entrar en contacto con lo que nos rodea, que él lo llama "curiosidad", pasamos a un proceso de reflexión sobre esa realidad para lograr leer. Este es el método que Freire nos mostró "la posición de quien indaga constantemente acerca de su propia práctica, acerca de los hechos en que se halla envuelto..." y él le denomina "posición curiosa". Es la curiosidad por conocer, por analizar cuanto le rodea a la persona que conoce antes de concentrarse en las formalidades de la enseñanza en las escuelas. Sin embargo, La educación bancaria no la estimula. Por el contrario, su tónica reside en matar en los educandos la curiosidad, el espíritu investigador, la creatividad. Y por ello es que insisto que este libro sin mencionar a Freire, retoma y aplica su enfoque para "fortalecer los proceso de aprendizaje" en una localidad muy particular por sus características: Sarchí.

La posterior lectura de la palabra no puede prescindir de la continuidad de la lectura de la realidad con la que convive. La lectura no debe constituirse en un acto de memorización, un acto mecánico que no le diga nada al discente; de ello se encarga la educación bancaria. Por el contrario, ésta debe ser una forma de encontrarse con otros mundos, otras realidades o la realidad que tiene al lado y que no es posible verla a simple vista. A partir de la lectura del mundo se puede generar la escritura, la creación, el re-vivir y ahora diría yo... la multiculturalidad. La lectura debe conducir al sujeto a ser protagonista de su propia historia y en esa medida, el aprendizaje no puede ser memorístico; la formación implica un reto: la comprensión, el análisis, la crítica a la realidad inmersa en el texto y su aprehensión. Por ello, las visitas guiadas, el análisis de los valores que coexisten en el texto ( $y$ diferenciarlos de los disvalores), la investigación a partir de la realidad que se vive, la explicación de las causas y efectos, son técnicas que inducen

\footnotetext{
*Este texto corresponde a la presentación del libro: "El módulo didáctico: La lectura: habilidad para transversalirzar la singularidad de un cantón”, llevada a cabo en el Museo Regional de San Ramón el 6 de abril de 2017.
} 
a abrir la mente de los niños y niñas hacia "el condicionamiento histórico-sociológico del conocimiento".

Freire además planteaba que es muy importante la búsqueda de la identificación en ese proceso de aprender. Conocer el nombre de la persona que es un actor significativo en la comunidad y utilizarlo, pasa por saber quién fue don Eloy Alfaro, por ejemplo; probablemente el niño o la niña escuchó muchas veces mencionar ese nombre pero no conocía a profundidad de quien se trataba. Sin embargo, ese discente al conocer los detalles de quien fue don Eloy y qué hizo logra una identificación con su propia actividad y en consecuencia, aparece un desafío a partir de su actividad crítica y del objeto que es conocido. Esa relación es lo que importa, dice Freire. Es la relación que se establece cuando el discente dibuja a don Eloy tal como se lo imagina y luego, van a visitar su taller y conoce su herencia expresada en los muebles, las carretas, los dibujos y sobre todo, aquel patrimonio intangible expresado en los valores que transmitió a sus hijos que también son artesanos.

En el otro lado de la acera, encontramos a "Los llamados "ignorantes" en las concepciones clásicas, son para Freire hombres y mujeres cultos, a los que se les ha negado el derecho de expresarse $y$ por ello son sometidos a vivir en una "cultura del silencio", plantean Varela y Escobar en la rica introducción que escribieron a uno de los textos de Freire menos conocidos: La importancia de leer $y$ el proceso de liberación. La palabra ignorante en nuestro medio tiene una connotación peyorativa, porque el mismo diccionario nos indica como una de sus acepciones que significa una "persona sin cultura o conocimientos". Pero en la concepción freireana ésta es una oportunidad para alfabetizar a esos "ignorantes" pues solamente se debe develar el mundo que les rodea, para que comprendan su propia cultura, la aprecien y recuperen la memoria que les permita reflexionar y aprehender su realidad para transformarla. Así pueden romper con la cultura del silencio que estos autores mencionan y expresarse. Hago una analogía entre esta expresión y los niños y niñas que aprenderán con este módulo didáctico. Reconocer los valores (respeto, solidaridad, trabajo, compromiso, humildad, disciplina) a través de personas que viven en nuestra sociedad (Carlos Chaverri, Eloy Alfaro, Antonio Alfaro -Toño Tajona- Manuel Jiménez, Claudio Rodríguez, doña Mela) y que son modelo en ésta, es una forma de leer la realidad para pronunciarla, para conocerla críticamente y no permitir que otros la mancillen, la roben o la transformen para su propio o mezquino beneficio.

En una comunidad como Sarchí, permeada por el turismo que se reduce comúnmente a una actividad netamente comercial, es indispensable que las nuevas generaciones comprendan de dónde salieron sus arquitectos y cómo se forjaron los valores que subyacen en la comunidad. Imagino en un sentido práctico, que el turismo que se ofrezca en el futuro no se reduzca a comprar chunches, sino que Sarchí pueda singularizarse ante el proceso de globalización. Así, el turista vendrá a conocer y comprender las particularidades de una región costarricense, a saborear su cultura y no a ver "más de lo mismo" y volver a su país tal como vino. Carlos Fuentes expresaba una frase muy pertinente: "No hay globalidad que valga sin localidad que sirva" ${ }^{2}$, para señalar que ante el fenómeno avasallador de la globalización, los países menos favorecidos, pobres, los del sur, deben fortalecer sus valores locales. Precisamente, ese es el camino que Sarchí y otras comunidades costarricenses deben tomar, pero éste se inicia con la formación de jóvenes conscientes de lo que tienen y cómo deben fortalecerlo para hacer del turismo una actividad económica que podría traer más beneficios y no pérdidas de nuestra identidad, maniqueísmo de nuestra cultura o efectos letales en nuestra adolescencia como ya sucede en otras regiones del país.

${ }^{2}$ Carlos Fuentes, En esto creo, op. cit., p.331 
La formación que se podrá dar a niños y niñas costarricenses a través de esta herramienta didáctica, estará rodeada por un marco de referencia que es histórico-local y no por un constructo rígido y universal que no le dice nada al aprendiente porque le es desconocido, lejano, abstracto. Por el contrario, el módulo didáctico permitirá que ese marco se desprenda de su propia realidad, se apropien de ella para transformarla si fuera necesario, o para enriquecerla y mantenerla como sujetos cognoscentes que son. La práctica de la artesanía pareciera una actividad común, ordinaria o habitual en Sarchí; podría ser considerada una "polada", despreciable por pueblerina y por lo tanto, con potencial de extinción. Esa práctica que se vuelve cada vez más cotidiana y por tanto invisible, podría llegar a extinguirse o comercializarse para que sea solo propiedad de unos pocos o ser transformada, simplificada, anulada, a bajo precio para que el producto se venda fácilmente. Es entonces cuando la comprensión, más que la información es necesaria en el acto educativo. Adueñarse de su propia realidad para comprenderla; alfabetizarse para construir el mundo y decir su propia palabra.

También encuentro otro elemento escondido en el módulo didáctico, que yo considero es parte de la cultura. Es la protección de la naturaleza, como un principio más que el libro incluye a partir del árbol de Guanacaste, como otro proveedor de materia prima para las artesanías. Este elemento es trabajado en el módulo didáctico como una actividad de mediación que también pretende pronunciar el mundo, llevar a los niños y las niñas hacia el conocimiento para que adquieran consciencia de la importancia de la conservación de la naturaleza. Quizá faltó aquí demostrar no solo de dónde viene la madera, sino cómo se puede adquirir sin hacer daño al ambiente, pero como dije al principio, éste es un elemento escondido en el libro pues no hay que olvidar que su eje principal es la cultura.

Conversando con una amiga que es maestra de larga data, le hablaba del libro sin que ella lo conozca, y describiendo su estrategia y contenido reaccionó inmediatamente para decirme que es un texto que no se restringe a Sarchí, a las escuelas de
Sarchí, sino que puede ser aplicado a nivel nacional. Así, discutíamos que este módulo didáctico puede ser la guía para que las escuelas de otros cantones la adapten a sus personajes y actividades propias e inmediatamente pensé en los trapiches ramonenses. Pero además, qué hermoso sería que en todas las escuelas del país se estudiara la cultura sarchiseña y se apropiaran de sus valores y personajes, para que una realidad poco conocida actualmente, se transforme en un modelo nacional y que puedan "pronunciar el mundo", su mundo.

Al terminar la lectura me quedó una idea paseando en mi cerebro, como un desafío para el Ministerio de Educación Pública y es la siguiente: ¿Por qué no se elaboran textos como éstos para otras comunidades costarricenses, que pudieran permitir que la lectura las invada y vivifiquen para que así puedan destacar sus singularidades? La transversalidad, la formación de valores, la contextualización y la participación comunitaria que permita enriquecer la realidad local tal como las plantea el MEP, serán cometidos que se verán facilitados con este módulo didáctico que Alicia y Gilberto nos entregan hoy.

Creo que la teoría freiriana sigue vigente con más fuerza que nunca. Mientras la globalización nos sigan avasallando, como parte de las políticas neoliberales -expresadas en la privatización, el comercio desbocado, la homogenización de la cultura, la inequidad y muchas otras característicasla educación cumple un papel fundamental, pero no cualquier enfoque educativo, no aquel memorístico, bancario y superficial, sino un enfoque que Freire nos enseñó hace ya casi cincuenta años y que se concreta en este libro. Gracias Alicia y Gilberto por este aporte; ojalá se reproduzca muy rápido.

¡Muchas gracias!

"Estudiar seriamente un texto es estudiar el estudio de quien estudiando lo escribió", dice Freire. 


\section{Referencias bibliográficas}

Freire, P. (2004). La importancia de leer y el proceso de liberación. 16. ed. México, D.F.: Siglo XXI. Disponible en: http://ceiphistorica.com/ wp-content/uploads/2015/12/Paulo-FreireLa-importancia-de-leer-y-el-proceso-deliberaci\%C3\%B3n.pdf

Freire, P. (1981). La importancia de leer [Conferencia]. Disponible en: http://perio.unlp.edu.ar/ catedras/system/files/la_importancia_del_ acto_de_leer.pdf

Fuentes, C. (2008). En esto creo. México: Alfaguara, p. 331. Citado en Gasperín, R. y Garza, V. Testimonios de Carlos Fuentes respecto a la globalización y los sistemas de creencias. EN-Claves del pensamiento, 8(16): 172, juliodiciembre 2014.

García Retana, J. (2016). Compromiso y esperanza en educación: Los ejes transversales para la práctica docente según Paulo Freire. Educación: Revista de la Universidad de Costa Rica, 40(1):113-132. Disponible en: http:// revistas.ucr.ac.cr/index.php/educacion/ article/view/14649/22917

Varela, H. y Escobar, M.(1986). Introducción. En: Freire, P. La importancia del acto de leer y el proceso de liberación. 4 ed. México, D.F.: Siglo XXI, pp. 8-19. Disponible en: http://ceiphistorica.com/wp-content/ uploads/2015/12/Paulo-Freire-Laimportancia-de-leer-y-el-proceso-deliberaci\%C3\%B3n.pdf 